\title{
ANALYSIS OF GEAR MILLING AT VARIOUS SPEEDS, TIME AND FEED RATES
}

\author{
K. A. Oladejo ${ }^{1}$ and K. T. Oriolowo ${ }^{2}$ \\ 1 DEPARTMENT OF MEChANICAL ENGINEERING, OBAFEMI AWOLOWo UNIVERSITY, ILE-IFE, NIGERIA \\ 2 DEPARTMENT OF INDUSTRIAL AND PRODUCTION ENGINEERING, UNIVERSITY OF IBADAN, NIGERIA \\ E-mail Addresses: ${ }^{1}$ oladejok@oauife.edu.ng, ${ }^{2}$ kolaorry@gmail.com
}

\begin{abstract}
Spur gears are the most commonly used gears for mechanical power transmission. Form-milling the tooth of involute spur gear involves specification of the cutting speed for the work piece material and feedrate of the milling cutter. The speed and feedrate selection for such cutting has a strong link with the completion period of the machining exercise, which indirectly also determines the cost of producing the gears. This paper presents a study carried out in establishing a multiple linear regression model for determining time required for form-milling an involute spur gear tooth at varying speeds and feedrates on a milling machine. Five spur gears, of 15-teeth each, with pressure angle 200 , and module $2.8 \mathrm{~mm}$, were experimentally milled on a universal milling machine, while the time for the completion of each tooth at different speeds and feedrates were recorded and analyzed on the platform of SPSS 12.0, where the data were subjected to $t$-test, ANOVA analysis and optimality test. The model generated $t=$ $f(s, f)$, gave coefficients $\beta_{0}, \beta_{1}$ and $\beta_{2}$ as $0.281,-0.005$, and -0.03 respectively. The test confirmed the coefficient as being significant to the adopted model and the ANOVA analysis showed the correlation between speeds and feedrates for cutting a tooth of a spur gear. Thus, as the cutting speed and feedrate increases, cutting time reduces. The model will serve as a useful tool in preparation of cost estimate in machining of involute spur gear.
\end{abstract}

Keywords: Cutting speed, feedrate, time, form-milling, mathematical model, spur gear tooth

\section{INTRODUCTION}

In milling, a multi-toothed cutter, rotating at a fixed position on the machine, shapes the work as it is traversed across the cutter. The work is firmly secured on the machine table which can be adjusted to set the depth of cut and can be moves in at least two directions in the horizontal plane. In some machines, a vertical traverse also is possible [1]. In the manufacture of metallic components using conventional machine tools, cutter tool wear, its effects on surface finish, and cutter tool failure provide major limitations to the achievement of economic production $[2,3]$.

Machinability is the term used to describe how easily a material can be cut to the desired shape with respect to the tooling and machining processes involved [4]. In machining operation, tool life achieved, metal removal rate, component as well as the shape of the chips can be used to measure machinability. The machinability index can be significantly affected by the properties of the material being machined, properties and geometry of the cutting tool, cutting conditions employed and other miscellaneous factors such as rigidity of the machine, cutting environment, etc. Machining productivity can be significantly improved by employing the right combination of cutting tools, cutting conditions and machine tool that will promote high speed machining without compromising the integrity and tolerance of the machined components. These peculiar characteristics generally impair machinability.

Form milling is the process of machining special profile composed of curved and straight lines. It is done with milling cutter shaped to the profile to be cut. The more common form of milling operation involves milling half-round recesses, beads and quarter-round radii on work pieces. Several studies have been presented in this area of study but without specific one on the generation of model for predicting the period of milling involute spur gear tooth using milling machine. The procedure for cutting gear and cutting tool selection has been established in 
literature while the influence of feedrate, cutting speed, and tool wear on case-hardened gear is also presented in the literature, [5]. The effect of cutting speed and feed rate on cutting forces were discussed in [6], with analysis of the three components of the cutting forces measured using strain base gauge dynamometer. They established that increasing the cutting speed increases cutting force; and that intermediate cutting speed increases built up formation tendencies.

A revelation was also made in an earlier work [7], that aggressive feedrate increases residual stress and penetration depth. In considering cutting speed, feedrate and the side cutting edge angle (SCEA) of the tool as the independent variables and suggested that dry turning of hardened., stainless tool steel could be performed using coated TiCN based cement and coated carbide cutting tools with $5^{0}$ SCEA at selected cutting speed and feedrate combination. This was a heat treatment based exercise. The influence of preheating on the performance of circular carbide inserted in end-milling operation of mild steel was reported in [8]. This established that feed rate and cutting speed have considerable effect on surface roughness and tool wear in the cases of both hot and room temperature machining. Alberti, et al. [9] developed an algorithm for the design of a system for selecting parameters in the cutting process of milling and high-speed milling. Their algorithm was based on optimizing the operation cost with the aim of obtaining the parameters that take into account all the existing restrictive factors included in machining operations. Applying their method helps to make the right decision on the optimal parameters in mill and high-speed mill operations as applied to the machining processes in milling operations, a reduction in processing times for both conventional and high speed milling operations while ensuring optimal finishing conditions.

Cost of machining could be analyzed by observing and considering tool wear using explicit mathematical relationships, but stochastic nature of tool wear provides an obstacle to the achievement of optimal production conditions [10]. By using tool wear to analyze cost of machining, there is a range of processes variables to indirectly measure the effects of tool wear such as using on-line electronic equipment to measure: motor power, spindle torque or even the current drawn by a.c. feed drive servometers [3]. Ming-Chyuan, et al., [11, 12, 10], established models for wear, tool life, and initial cutting condition in terms of force ratios with nonlinear regression analysis techniques; but some other parameters like time, feed rate were not considered. Deepak, [13] observed that it is necessary to optimize the cutting speed and feed rate simultaneously in order to obtain an economical metal cutting operation. The higher the machining rate, the shorter the tool life. In other words the lower the machining cost, the higher is the tool cost and vice versa. However, not all machining conditions affect tool life and machining rate equally. There are therefore optimum conditions, which result is minimum overall cost, [14], coupled with technologist experience that tool life is longer at low cutting speeds but if the force intensity is too high, it could result in chipping and significant reduction of tool life. The objective of this study is to generate a mathematical model for determining the time involved in form-milling of an involute spur gear on a conventional universal milling machine; which is indirectly useful for estimating the cost of producing gear.

\section{MECHANICS OF FORM-MILLING GEAR TOOTH}

The cost of manufacturing components includes all labour charges and overheads. These costs are timedependent and can be reduced by the use of correct tools and optimal machining settings. The use of freemachining materials may be significantly less expensive than other materials that cannot be machined at such high speeds and cause problems in removal of swarf. In the case of form milling gear tooth, it is referred to as milling cost (C), which is directly proportional to the duration for the operation and depends on the following: cutting tool $\left(\mathrm{C}_{\mathrm{t}}\right)$, machine tool $\left(\mathrm{M}_{\mathrm{t}}\right)$, cutting feed ( $\left.\mathrm{f}\right)$, cutting speed (s), competency of operator $\left(\mathrm{C}_{0}\right)$, required accuracy $\left(\mathrm{r}_{\mathrm{a}}\right)$ and work piece material (M) [15].

Mathematically this is expressed as:

$\mathrm{C}_{\mathrm{m}}=f\left(\mathrm{C}_{\mathrm{t}}, \mathrm{M}_{\mathrm{t}}, \mathrm{f}, \mathrm{s}, \mathrm{C}_{\mathrm{o}}, \mathrm{M}_{\mathrm{w}}, \mathrm{r}_{\mathrm{a}}\right)$

For a case where, reliable tool, milling machine, component machinist, and standard work piece are made available, equation (1), can be reduced to:

$\mathrm{C}_{\mathrm{m}}=f(\mathrm{t})=f(\mathrm{t}, \mathrm{s})$

$f(\mathrm{t})=f(\mathrm{f}, \mathrm{s})$

This allows the investigation of the period required to perform form-milling a tooth of involutes spur gear at varying feed and speed on a standard material. Cutting speed is the rate at which the cutting edge of the tool moves past the stationary work piece and is measured in meters per minute $(\mathrm{m} / \mathrm{min})$. For a given 
material there will be an optimum cutting speed for a certain set of machine conditions, in which the spindle speed (rpm) can be calculated from the cutting speed. Factors affecting the calculation of cutting speed are: the material being machined, the material which cutter is made from, the economical life of the cutter (the cost to regrind or purchase new). Cutting speeds for different materials are available in manufacturers and suppliers catalogue. The most common materials are available in reference books or charts but will always be subjected to critical adjustment depending on the cutting conditions.

Table 1: Cutting speeds for various materials using $H$.

\begin{tabular}{lccc}
\multicolumn{4}{c}{ S. S. tools } \\
\hline \multirow{2}{*}{ Material } & \multicolumn{3}{c}{ Cutting speed (m/min) } \\
\cline { 2 - 4 } & Drilling & Turning & Shaping \\
\hline Mild steel & 25 & 30 & 20 \\
Cast iron & 15 & 15 & 10 \\
Stainless & 20 & 20 & 15 \\
steel & 55 & 60 & 30 \\
Bronze & 50 & 60 & 30 \\
Brass & Adapted from Sharma [15]
\end{tabular}

The spindle speed is measured in revolutions per minute (rpm) and is calculated using the recommended cutting speed of the material under study. The gear cutter is mounted on the spindle. Spindle speeds and feed rates are essential machining parameters in a milling machine. In most machines, cutting speed is regulated through the feed rate. The required feed rate can be extremely variable depending on the workpiece, and the sharpness of the cutting tool. The formula to estimate the spindle speed value is given by, [16] as,

$N=\frac{1000 S}{n d}$

In (4), S is the cutting speed, $\mathrm{m} / \mathrm{min}$ and $\mathrm{d}$ is the diameter of the cutter, $\mathrm{mm}$.

Feed is the rate at which the work is fed into the cutter. Feed per tooth (FPT) is the amount of material that should be removed by each tooth of the cutter as it revolves and advances into the work. Table 2 illustrates the recommended FPT for some common metals. As the work advances into the cutter, each successive tooth advances into the work on equal amount, producing chips of equal thickness. The thickness of the chips along with the number of teeth in the cutter forms the basis for determining the rate of feed. The ideal feed rate may be determined as follows:

Feed $=\mathrm{N}_{\mathrm{t}} \times($ FPT $) \times \mathrm{S}$

Where, $\mathrm{N}_{\mathrm{t}}$ is the number of teeth on the cutter.

Table 2: Recommended FPT using H.S.S and Cemented - carbide tools

\begin{tabular}{lcc}
\hline \multirow{2}{*}{ Material } & \multicolumn{2}{c}{ Form-relived cutters (mm) } \\
\cline { 2 - 3 } & HSS tool & $\begin{array}{c}\text { Cemented } \\
\text { carbide }\end{array}$ \\
\hline $\begin{array}{l}\text { Cast iron, } \\
\text { (medium) }\end{array}$ & 0.10 & 0.13 \\
$\begin{array}{l}\text { Stainless steel } \\
\begin{array}{l}\text { Brass and bronze } \\
\text { (medium) }\end{array}\end{array}$ & 0.05 & 0.08 \\
$\begin{array}{l}\text { Tool steel, } \\
\text { (medium) }\end{array}$ & 0.01 & 0.01 \\
\hline
\end{tabular}

\section{MATERIALS AND METHODS}

The approach employed for this study involves cutting seventy-five spur-gear teeth at varying speeds and feeds, measuring the time to complete each formmilling exercise, analysis of data recorded in the experimentation for model formulation.

\subsection{Procedure for optimum selection of speed}

One of the most important factors affecting the efficiency of a milling operation is cutting speed. The cutting speed of a metal may be defined as the speed, in meters per minute $(\mathrm{m} / \mathrm{min})$ at which the metal may be machined efficiently. For a given material, there will be an optimum cutting speed for a certain set of machining conditions, and from which the spindle speed (rpm) could be calculated. Factors affecting the selection of cutting speed are: the material being machined, the material the cutter is made from (HSS, Carbide, etc), and the cost to regrind or purchase new cutter, compared to the quantity of parts being produced based on the assumption that optimum cutting conditions exist. Table 3 gives the cutting speeds for common materials under one set of conditions. The conditions are a tool life of 1 hour, dry cutting, and at medium feeds. These cutting speeds may change, if for instance, adequate coolant is available or an improved grade of HSS used. 
Table 3: cutting speeds for various materials on milling machine

\begin{tabular}{ccc}
\hline \multicolumn{3}{c}{ Cutting Speed (m/min) } \\
\hline \multirow{2}{*}{ Materials } & High Speed & Carbide tool \\
& Steel & $300-600$ \\
Aluminum & $75-105$ & $45-75$ \\
Alloy Steel & $15-18$ & $61-120$ \\
Bronze & $24-45$ & $40-60$ \\
Cast Iron & $18-24$ & $120-180$ \\
Mild Steel & $30-38$ & \multicolumn{2}{c}{${ }^{*}$ Adapted from Krar and Check, [16]. }
\end{tabular}

\subsection{Form-milling of Spur Gear Teeth}

The optimum speed $\left(\mathrm{S}_{2}\right)$ and feed $\left(\mathrm{F}_{2}\right)$ were defined. Since the cutting speeds given by the manufacturer or supplier in Table 3 are in ranges, two different cutting speeds were selected, one above $\left(S_{2}\right)$ and the other below $\left(\mathrm{S}_{2}\right)$. Though the selected speeds are still within the allowable range of the chosen materials, the equivalent feeds were calculated for each of the speeds and represented as F5, F4, F3, F2, and F1 respectively. Moreover, with the aid of a dividing head, gear teeth were milled on mild steel on a universal milling machine with machine specification presented in Table 4. Indexing is used to divide the circumference of a work into equally spaced divisions. For this project, three gear teeth were milled on the work piece (mild steel) by making the speed constant and while varying the feeds. This produces 15 gear teeth. Similarly for each of the remaining speeds, 15 gear teeth are achieved and this gives a total of 75 gear teeth on all. The specimens are shown in Figure 1. The time taken to cut each gear tooth was recorded with a stopwatch as shown in Table 5. The mean of the time taken to cut three gear teeth at the same speed and feed was calculated to minimize experimental error and also improve the sensitivity of the treatment effect analysis as shown in Table 6.

\section{Table 4: Specification of the milling machine used for} form-milling gear teeth

\begin{tabular}{lc}
\hline Name & $\begin{array}{c}\text { 2E Bridgeport Leicester } \\
\text { machine }\end{array}$ \\
\hline Voltage & $440 \mathrm{~V}$ \\
Phase & 3 \\
Frequency & 50 \\
Full-load current & $9.1 \mathrm{~A}$ \\
Spindle Motor & $7.3 \mathrm{~A}$ \\
Current & $110 \mathrm{~V}$ \\
Control Voltage & $16 \mathrm{~A}$ \\
Full Interrupt & \\
Capacity & \\
\hline
\end{tabular}

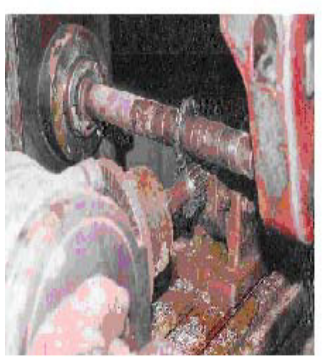

(a)

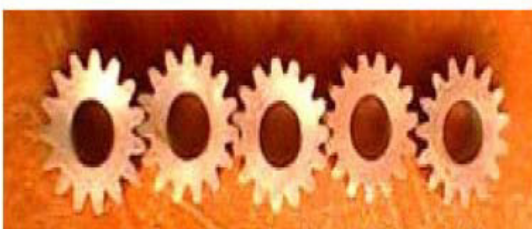

(1) (2) (3)

(4)

(5)
Figure 1: Milling operation and specimens of spur gear produced

\subsection{Data Analysis and Model Formation}

The data, in Table 6, were subjected to statistical analysis on the platform of SPSS 12.0 using multiplelinear regressions to formulate the relationship between the dependent variable $t$ (Time), and the two independent variables s (Speed) and $\mathrm{f}$ (Feed). The equation that best fits the regression model was established in $[17,18]$ as,

$\mathrm{t}=\beta_{0}+\beta_{1} \mathrm{~S}+\beta_{2} \mathrm{~F}+\mathrm{e}_{\mathrm{i}}$

In (6), $\mathrm{t}$ is the time $(\mathrm{min}), \mathrm{S}$ is the speed $(\mathrm{m} / \mathrm{min}), \mathrm{F}$ is the feed, $(\mathrm{m} / \mathrm{min}), \beta_{0}$ is a constant, $\beta_{1}$ and $\beta_{2}$ are coefficients of the $S$ and $F$ respectively, and $e_{i}$ is residual values.

\section{RESULT AND DISCUSSION}

The data used in this analysis were obtained from the experiment result of form milling involute spur gear tooth at varying cutter speed and the feedrate. The model equation which can be used to determine the time required for the gear cutting at various speeds and feed rates were derived from multiple linear regression model with the SPSS 12 software as a tool. Each coefficient in the equation was significant to the adopted model. There is non-significant correlation between time and speed $(r=0.00, p>.05)$; between time and feedrate $(r=-0.340 ; p>.05)$. But there is negative correlation between time and feedrate $(r=$ $-0.505, \mathrm{p}<.05)$. This inverse relationship indicated that decrease in time will lead to increase in feedrate and vice-versa. Speed and feedrate yielded a coefficient of multiple regression (R) of 0.537 and multiple correlation square of 0.288 . This shows that $29 \%$ of the total variance of time is accounted for by the linear combination of the speed and feedrate. It was revealed that both speed and feedrate had significant joint effect on time $[\mathrm{F}(2,22)=4.46$; $\mathrm{p}<$ $0.5]$.

Based on this, result, it can be concluded that there is significant joint contribution of speed $(\beta=-0.194 ; \mathrm{t}=$ 
-1.015; $\mathrm{p}>0.05)$ and federate $(\beta=-0.571 ; \mathrm{t}=-$ 2.1986; $\mathrm{p}<0.01$ ) on time. Hence, the model can be drawn from the analysis as $\mathrm{t}=0.281-0.005 \mathrm{~S}-0.003 \mathrm{~F}$ $+\mathrm{e}_{\mathrm{i}}$ as earlier established in $[17,18]$.

Figure 2 and Figure 3 shows that feedrate is inversely proportional to the Time spent in gear cutting, also to the speed of the gear tooth cutter, while Figure 4 shows that speed of the gear tooth cutter is inversely proportional to the feedrate of the work.

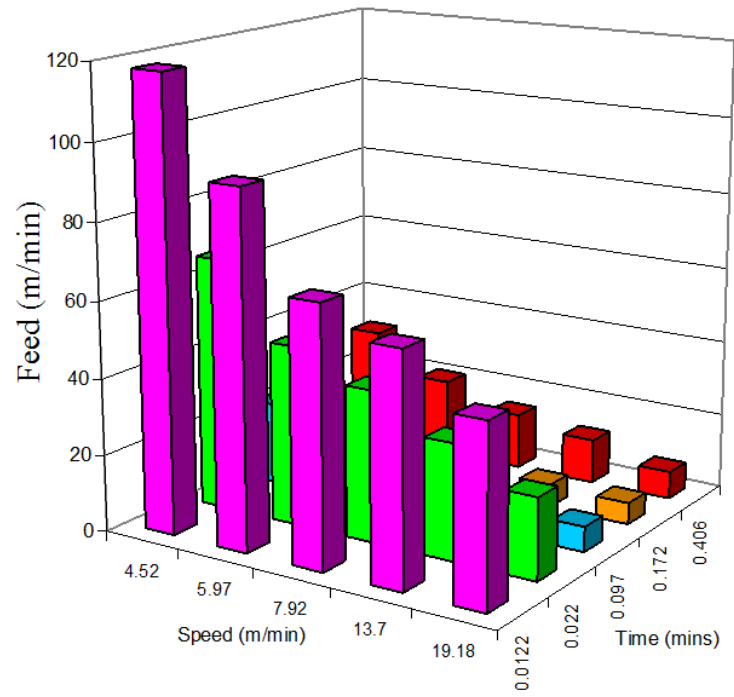

Figure 2: Graph Showing Relationship between Feedrate, Speed of theGear tooth and Time spent.

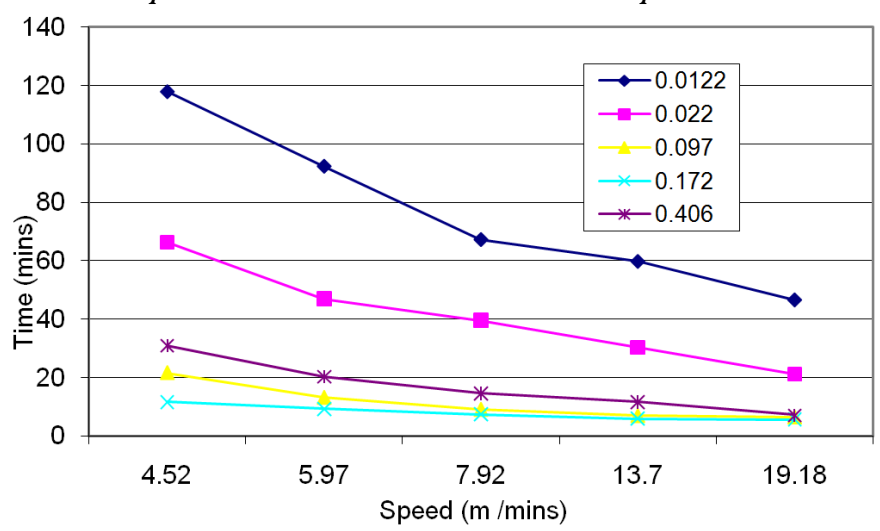

Figure 3: Graph Showing Relationship between Feedrate, Speed of the Gear tooth cutter and Time spent

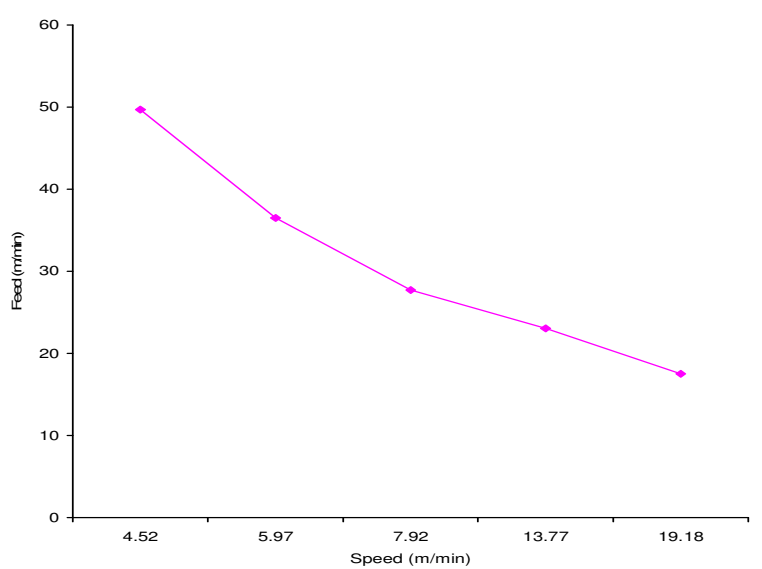

Figure 4: Graph showing relationship between feedrate of the work and the Speed of the Gear Tooth cutter

\section{CONCLUSION}

This paper present a mathematical model developed for the prediction of the effect of rotational speed, and feedrate of cutting tool in the duration of form-milling tooth of an involutes spur gear made of mild steel. The following conclusions were derived from the result of this study:

- A multiple-linear regression analysis can be employed easily for developing model for predicting duration of cutting teeth of involute spur gear in the workable parameter of formmilling mild steel.

- Time taken for cutting spur gear tooth reduces with increase in the cutting speed and feedrate respectively.

- The minimum time for allowable speed and feedrate for the form-milling operation was found to be 5.72 minutes.

- The responses (as per duration) can be effectively controlled by substituting appropriate values of the process variable into the mathematical model developed.

- The model formulated will enable the gear manufacturer to effectively estimate the time required to produce an involute gear at various speeds and feedrates: by estimating the minimum feedrate, by estimating the minimum time taken will make it easier to do the appropriate costing of the task.

\section{ACKNOWLEDGEMENT}

The authors are grateful to Mr. Siji at Machine Shop of Centre for Energy Research and Development (CERD), OAU, Ile-Ife; and Mr. D. A. Ojebisi of Machine and Fabrication Workshop of Mechanical Engineering, The Polytechnic, Ibadan, for the cutting of the involute spur gears.

\section{REFERENCES}

[1] Love, G., The Theory and Practice of Metalwork, $3^{\text {rd }}$ edition, England: Pearson Education Limited, England, 1999.

[2] Fraticelli, B. M. P., "Tool Wear effect Compensation under Sequential Tolerance Control", International Journal of Production Research, 37, (3), 1999,pp 639.

[3] Pai, P. S. and Rao, P. K. R., "Acoustic Emission for Tool Wear Monitoring in Face Milling", International Journal of Research, 40 (5), 2002, pp 1081. 
[4] Ezugwu, E. O., "High Speed Machining of Aero-engine Alloys", Journal of the Brazilian Society of Mechanical Sciences and Engineering, 26,(1), 2004, pp. 78-83.

[5] Rech, J. and Moisan, A., "Surface Hardened Steels", International Journal of Machine Tools and Manufacture, 43, Issues 5, 2007, pp. 543-550.

[6] Korkut, I. and Donertas, M. A., "The influence of feed rate and cutting speed on the cutting forces, surface roughness and tool chip constant length during face milling", International Journal of Material and Designs, 28, Issue 1,2005, pp. 308-312.

[7] Jiang, H, Shivpuri, R, Cheng, X, Bedekar, V, Matsumoto, Y, Hashimoto, F, and Watkins, T., "Effect of feed rate, workpiece hardness and cutting edge on subsurface residue stress in the hard turning of bearing steel using chamfer hone cutting edge geometry", International Journal of Materials Science and Engineering, 394, Issues 1-2, 2007, pp. 238-248.

[8] Amin, N. K. M. N., Abraham, I., Khairusshima, N., and M. I, Ahmed, "Influence of pre-heating on performance of circular carbide inserts in end milling of carbon steel", Journal of Material Processing Technology, Vol. 185,2007, pp. 97-105.

[9] Alberti, M, Ciurane, J., and Casadesus, M., "A system for Optimizing cutting parameters when planning milling operations in high-speed machining", Journal of Material Processing Technology, 168, Issues 1, 2007, pp. 25-35.

[10] Oraby, S. E, and Hayhurst, D. R., "Tool life determination based on the measurement of wear and Tool force ratio variation", International Journal of Machine Tools and Manufacture, 44, 2004, pp. 1261-1269.

[11] Ming-Chyuan, L. and Kannatey, J. E., "Analysis of sound signal generation due to flank wear in turning", Trans ASME Journal of Manufacturing Science and Engineering, 124, (4), 2002, 79.

[12] Kumar, S. A, Ravindra, H. V, and Srinivasa, Y. G., "Inprocess tool wear monitoring through time series modeling and pattern recognition", International Journal of Production Research, 35, (3), 1997, 739.

[13] Deepak, S. S. K., "Cutting speed and Feed Rate Optimization for minimizing production Time of Turning process", International Journal of Modern Engineering Research (IJMER), Vol. 2, Issue 5, 2012, pp. $3398-3401$.

[14] Trmal, G. J, and Bach, P., "Economy of Titanum Milling”, MM Science Journal, 2008, pp. 65 - 70.

[15] Sharma, P. C., Machine Tools and Tool Design, New Delhi: S. Chand and Co, 2004.

[16] Krar S. F. and Check, A. F., Technology and Machine Tool $5^{\text {th }}$ edition, New York: Glencoe/McGraw - Hill, New York, 1997.

[17] Johnson, A. R., Miller and Freund's Probability and Statistics for Engineers, $6^{\text {th }}$ Edition. New Delhi: Prentice - Hall of India Private Limited, 2003.

[18] Owen, F, and Jones R., Statistics , Financial Times, $5^{\text {th }}$ Edition London: Pitman Publishing, 2000. 